\title{
Auxin and cytokinin act during gynoecial patterning and the development of ovules from the meristematic medial domain
}

\begin{tabular}{|r|l|}
\hline Journal: & WIREs Developmental Biology \\
\hline Manuscript ID: & Draft \\
\hline Wiley - Manuscript type: & Advanced Review \\
\hline Date Submitted by the Author: & n/a \\
\hline Komplete List of Authors: & $\begin{array}{l}\text { Sehra, Bhupinder; North Carolina State Universtiy, } \\
\text { Franks, Robert; North Carolina State University, Plant and Microbial Biology }\end{array}$ \\
\hline & $\begin{array}{l}\text { Auxin transport, Carpel margin meristem, Arabidopsis gynoecium, } \\
\text { PINFORMED, PGP/ABCB type auxin transporters }\end{array}$ \\
\hline $\begin{array}{r}\text { Choose 1-3 topics to } \\
\text { categorize your article: }\end{array}$ & $\begin{array}{l}\text { Inflorescence, Flower, and Fruit Development (FJAH) < Plant Development } \\
\text { Transcriptional Hierarchies (FBAA), Regulation of Size, Proportion, and } \\
\text { Timing (FAAF) < Establishment of Spatial and Temporal Patterns (FAAA) }\end{array}$ \\
\hline
\end{tabular}




\section{Article type: Advanced Review}

\section{Auxin and cytokinin act during gynoecial patterning and the development of ovules from the meristematic medial domain}

\section{Authors: \\ Bhupinder Sehra and Robert G. Franks* \\ Authors declare no conflicts of interest}

First author

North Carolina State University, Interdepartmental Program in Genetics

Second author

North Carolina State University, Department of Plant and Microbial Biology, rgfranks@ncsu.edu

\section{Abstract}

The gynoecium is the female reproductive structure of flowering plants, and is the site of ovule and seed development. The gynoecium is critical for reproductive competence and for agricultural productivity in many crop plants. In this review we focus on molecular aspects of the development of the Arabidopsis thaliana gynoecium. We briefly introduce gynoecium structure and development and then focus on important research advances published within the last year. We highlight what has been learned recently with respect to: 1 ) the role of auxin in the differential development of the medial and lateral domains of the Arabidopsis gynoecium; 2) the interaction between cytokinin and auxin during gynoecial development; 3 ) the role of auxin in the termination of the floral meristem and in the transition of floral meristem to gynoecium and 4) recent studies that suggest a degree of evolutionary conservation of auxin mechanisms during gynoecial development in other eudicots. 
Introduction

\section{Structure of the mature Arabidopsis gynoecium}

The Arabidopsis thaliana gynoecium is made up of two fused carpels, generating a tube-like structure ${ }^{1-6}$. Along its apical to basal extent, the mature Arabidopsis gynoecium can be divided into four structurally and functionally different regions: the stigma, the style, the ovary and the gynophore (Figure 1A). The most apically located structure, the stigma, allows for pollen to be received and to germinate. The stigma and the style together comprise the upper-most portion of the transmitting tract. The transmitting tract is a specialized tissue that supports pollen tube growth and allows the pollen cell to reach the ovules located in the ovary. The gynophore, the most basally located portion of the gynoecium, attaches the gynoecium to the rest of the plant.

The ovary makes up the largest portion of the gynoecium. Within the ovary, about 50 ovules will form attached to a septum that separates the ovary into two locules (Figure 1B). Each ovule contains a female gametophyte, a multi-cellular haploid structure that includes both the egg cell and the central cell. After a double fertilization event, the egg cell will form into the embryo and the central cell into the endosperm. Thus the fertilized ovules mature into seeds containing embryo and the endosperm components.

Unlike the stigma, style and gynophore regions that are radially symmetric, the ovary is bilaterally symmetric to an imaginary plane that bisects the septum (Figure 1B). The ovary can be divided along this axis of symmetry into medial positions (those close to the axis of symmetry) and lateral positions (further from the axis)(Figure 1C). Within the mature gynoecium the structures located in the lateral positions are termed valves and make up the majority of the wall of the gynoecial tube. The ovules, septum and abaxial replum are located in medial positions. The septum contains the lower portions of the transmitting tract that are required for pollen tube growth and ovule fertilization. Late in development of the maturing fruit, cells of the valve margins, (where the valves meet the abaxial replum) differentiate into a dehiscence zone (Figure 1). Cells of the dehiscence zone undergo a set of specialized differentiation programs so that the valves can separate from the replum (dehisce) and allow seed dispersal ${ }^{7}$.

\section{Development of the Arabidopsis Gynoecium}

The Arabidopsis gynoecium arises as a single, mound-shaped primordium in the center of the floral meristem, thus marking the beginning of stage 6 of floral development ${ }^{6,8}$. Floral stages are according to Smyth et al. ${ }^{8}$. At this early stage of development a degree of positional identity has already been assigned that distinguishes the medial and lateral regions of the primordium ${ }^{1}$. Different positional identities are evidenced by the expression of several genes including CRABSCLAW (CRC) and YABBY1 (YAB1) ${ }^{9-11}$ in the lateral domains and SHOOTMERISTEMLESS (STM) and SHATTERPROOF2 (SHP2) ${ }^{1,12,13}$ in the medial domain (Figure 1E,F). These different positional domains will give rise to different functional structures. Although a careful clonal analysis of the developmental progression has not been published, based on patterns of cell division and gene expression, the lateral domains are thought to give rise to the valves while the medial domain gives rise to the ovules, the septum and the abaxial replum. 
Early during floral stage 7, the mound shaped gynoecial primordium begins to morph into a tubeshaped structure that is still open at the ape ${ }^{8}$. Inside the tube, two meristematic ridges of tissue that span the apical-basal extent of the gynoecium form within the medial domain (Figure 1 C, D) ${ }^{1}$. These have been termed the medial ridges or alternatively the carpel margin meristems (CMMs). The meristematic nature of the medial ridge is indicated by the expression of STM ${ }^{12}$ (Figure 1F), a marker of meristematic regions, as well as by the ability of the cells of the medial ridge to give rise to organ primordia (e.g. ovules). Ovule primordia arise from the medial ridge during late stage 8 , as finger-like projections along the apical-basal extent of the ridge. These ovules continue to mature until stage 12 when the flower opens and the ovules are competent to be fertilized. Style and stigmatic tissues begin to differentiate in apical positions starting at late stage $9^{1,6}$.

\section{Evolutionary origin of the meristematic medial domain}

The Arabidopsis gynoecium is typically represented as a composite structure derived from the congenital fusion of two component carpels (Figure 1B) ${ }^{14}$. In an evolutionary sense the two carpels are thought to be modified leaves ${ }^{15,16}$. In this representation the margins of the two component carpels are seamlessly fused along the medial domain, and the medial domain is thought to represent the marginal regions of the component carpels. In this case the medial domain of the gynoecium would be evolutionarily derived from the leaf margin and the generation of meristematic fates in this position would likely reflect a developmental redeployment of the meristematic program along the organ margin.

An alternative possibility is that the ancestral Angiosperm carpel was ascidiate (cup-shaped) ${ }^{17}$ and in Arabidopsis the meristematic medial ridge that sits between the two carpels would reflect tissue that is derived from a shoot or an axis. In this representation, the meristematic medial domain would arise directly from the terminating floral meristem or could arise in an axillary position relative to the two component carpels. In either of these cases, the meristematic identity of the medial domain would not reflect a re-deployment at the leaf margin, but would be more similar to an inflorescence branch meristems forming in the axil of a rosette leaf or a floral meristem forming in the axil of a subtending bract. Although the "modified leaf margin" representation is much favored in the current literature, the matter is not fully resolved. Future investigations of the molecular developmental mechanisms of female reproductive meristem development in basal angiosperms and gymnosperms may help to resolve this question.

\section{Distinctive patterns of auxin transport and response differentiate lateral gynoecial domains from the meristematic medial domain}

\section{The auxin gradient model}

A variety of experiments over the past several decades indicate that proper synthesis, transport and response to the plant hormone auxin are required within the developing gynoecium for proper development and female reproductive competence (See sidebar). See Larsson et al. and Dresselhaus and Schneitz for a recent reviews ${ }^{18,19}$. One set of key experiments were those published by Nemhauser et al. ${ }^{20}$ in which developing gynoecia were transiently treated with the auxin transport inhibitor 1-N-naphtylphthalamic acid (NPA)(See sidebar). An analysis of the resulting morphological defects demonstrated an important role for auxin transport in the patterning of the gynoecium and lead to a model that proposed that patterning along the apical/basal axis of the gynoecium required 
the formation and action of an auxin gradient along this axis of the developing organ. In this model, high levels of auxin synthesis would be found at the apex of the gynoecium. Then through the action of basipetal (toward the base) transport of auxin, a gradient would form with high auxin concentrations at the apex and low concentrations at the base. The response of the cells to different threshold levels of auxin along this gradient would lead to the formation of gynophore, ovary, style and stigmatic tissues along the basal to apical extent of the gynoecium. Later efforts to visualize this auxin response gradient with the DR5-based auxin response reporters (see side bar) did reveal an auxin response maximum at the gynoecial apex, but no gradient of auxin response could be detected in more basal regions, thus calling into question tenets of this model ${ }^{18,21-24}$

\section{Early patterns of auxin response differ in medial and lateral gynoecial domains}

In 2014, two papers were published that carefully examined the patterns of auxin transport, and auxin response in the developing gynoecia ${ }^{21,22}$. Larsson et al. (2014) report the formation of two DR5 auxin response foci at the apex of the stage $5 / 6$ gynoecium, one focus located within each lateral domain ${ }^{21}$. These DR5 foci likely represent the positions of the individual carpel primordia as they are forming. Two additional apical foci located in the medial domain can be detected, however these form later in development. These medial DR5 foci are weakly and inconsistently detected in stage $6^{21}$ and become established more strongly and consistently during stage $7^{21,22}$. Thus the formation of the medial DR5 foci is delayed by 24-48 hours relative to the lateral foci. During stage 8 , the four apical foci of DR5 expression are transformed into a ring of apical expression that encompasses the entire apical tip of the gynoecium ${ }^{18,21-24}$.

\section{PINFORMED (PIN) family of auxin transporters}

Based on the expression patterns and timing of expression of genes required for auxin synthesis (i.e. TRYPTOPHAN AMINOTRANSFERASE OF ARABIDOPSIS1 [TAA1]/ (TRYPTOPHAN AMINOTRANSFERASE RELATED 2)[TAR2] and YUCCA-family genes -See side box) relative to the timing of the appearance of the DR5 foci, it is unlikely that the apical DR5 response foci are formed entirely by local auxin synthesis ${ }^{21,22}$. A variety of evidences suggest that the DR5 expression foci require directional transport of auxin. Both Larsson et al. and Moubayidin and Ostergaard report the expression patterns of PIN1, PIN3 and PIN7 auxin transporters during gynoecial development and highlight the functional importance of PIN1. At the earliest stage of gynoecium development, as the central portion of the floral meristem is transitioning into the gynoecial primordium (Stage 5 to 6), PIN1 protein is expressed in the epidermal cells and appears to transport auxin toward the apex and center of the developing gynoecial mound and toward the developing lateral DR5 $\mathrm{foci}^{21}$. The reduced expression of the DR5 lateral foci in the hypomorphic pin1-5 allele ${ }^{22}$ and the loss of valves observed in pin1 mutant gynoecia ${ }^{25}$ indicate that the PIN1 transporter is indeed important for the generation of the lateral DR5 foci, and subsequent valve growth.

As the gynoecial tube develops further, PIN1 transporters are expressed in the lateral domains in the L1 epidermal cell layer. Here the PIN1 transporter protein is polarly localized on the apical surface of the epidermal cells, orientated so as to transport auxin toward the apex of the gynoecium ${ }^{21,22,26}$. Within the medial domains, PIN 1 is not a strongly localized to just the apical surface of the cell, but rather is distributed evenly on all plasma membrane surfaces, suggesting a less polarized transport of auxin within the medial domain ${ }^{21}$. In addition, in the medial domain PIN1 is expressed throughout the internal cell layers (i.e. in the L2 and L3 mesophyll cell layers). This is in contrast to in 
the lateral domains where PIN1 is expressed chiefly in the epidermis and in the developing vasculature. Thus PIN1 localization and DR5 reporter expression data suggest that the auxin transport and response in medial and lateral domains is different from an early developmental stage.

Taken together these data suggest that the flow of auxin in the epidermis of the lateral domains is acropetal (toward the tip of the gynoecium) ${ }^{21,22}$, then back down through the forming vasculature ${ }^{21}$ similar to the reverse fountain model as proposed in the developing leaf ${ }^{27}$ (Figure 2). In contrast, in the medial domains it appears that the net flow of auxin may be less strongly directed when compared to the flows in the lateral domains. Based on patterns of expression of auxin synthesis genes (e.g. TAA1/TAR2/YUCCA-family members), both Larsson et al. (2013) and Hawkins and Liu (2014) suggest that auxin synthesis in basal portions of the gynoecium or in the receptacle of the flower may be important for the proper formation of the gynoecium ${ }^{18,28}$. Furthermore, Larsson et al. (2014) report a difference in the timing of the development of the vasculature in the medial and lateral domains using the IAA2:GFP reporter as a marker of early vasculature development; the lateral domain vasculature starts to develop by stage 5 while in the medial domain IAA2:GFP expression is not detected until stage $7-8^{21}$. Thus, the patterns of auxin transport and the timing of vascular development differs between the medial and lateral gynoecial domains during early development.

\section{Regulation of PIN1 subcellular polarity by PINOID kinase is required for proper medial domain development}

PID (PINOID) encodes an AGC-3 type protein kinase that is required for apicial (polar) localization of the PIN transporter proteins within the apical/basal context of individual cells ${ }^{29-31}$. PID acts to phosphorylate serine residues in the PIN transporters, thus resulting in the apical (polar) localization of the PIN1 protein ${ }^{32}$. Mutation of two of the PIN1 serine residues (substitution of serine with alanine and thus preventing phosphorylation) results in a constitutive apolar localization of the PIN1 transporter ${ }^{32}$ and in apical/basal patterning defects in the gynoecium that are similar to those observed in the hypomorphic pin1-5 mutant or after NPA treatment ${ }^{22}$. Furthermore the serine-toalanine substitutions in PIN1 condition the reduced expression of the DR5 reporter in the lateral apical foci.

Interestingly the DR5 medial foci and the DR5 apical ring are largely maintained in the pin1-5 and pid-8 mutants indicating that they are independent of polar PIN1 localization ${ }^{22}$. Moubayidin and Ostergaard propose that the medial foci are the result of the action of the transcription factors SPATULA (SPT) and INDIHISCENT (IND) that function to repress PID transcription in the medial domains ${ }^{23,26}$ thus resulting in the observed less polarized localization of PIN transporters in the medial domain.

Furthermore, the phosphorylated state of a serine residue can be mimicked by changing the serine residue to a glutamate residue, thus generating a constitutively pseudo-phosphorylated phosphomimic $^{32}$. When Moubayidin and Ostergaard expressed such a mutant PIN1 protein (PIN1:GFP $S 1,2,3 E$ ) from the PIN1 promoter, the phospho-mimic PIN1 protein was constitutively apically polarized, even in the medial domain, resulting in a split style phenotype similar to that observed in spt-12 ${ }^{22}$. In the PIN1:GFP S1,2,3E expressing plants, the medial DR5 foci were not detected, while the lateral foci were detected as in wild type. Thus the medial DR5 foci do not require strongly apical 
(polar) localization of PIN1, and in fact may require a greater degree of apolar PIN1 distribution. This greater degree of apolar PIN1 in the medial domains is important for DR5 foci in the medial domains and for the subsequent formation of the DR5 apical expression ring at stage 8 and the proper formation of style and stigmatic tissues. The Moubayidin and Ostergaard model further suggests that the medial DR5 foci promote the bilateral to radial transition at the apex of the gynoecium and the subsequent formation of the style, while the apical/basal gynoecial patterning defects are a result of a failure to form the lateral foci and the associated reduced growth of the lateral/valve domains.

Larsson et al. suggest that the drainage of auxin through the forming pre-vasculature may be required for carpel organ outgrowth in the lateral domains ${ }^{21}$. This is similar to what has been proposed to occur in developing leaves ${ }^{33}$. A disruption of auxin removal through the pre-vasculature (due to NPA treatment) would be expected to affect the lateral domains more severely than the medial domains, as the "reverse fountain" flow of auxin appears more predominant in the lateral domains. This may also contribute to the preferential growth of the medial domains over the lateral domain upon NPA treatment. This would provide a mechanistic explanation for the observation that the medial and lateral domains experience differential responses to the application of NPA ${ }^{21}$.

\section{Transient treatment with NPA results in ectopic expression of DR5 and expansion of medial domain markers}

Larsson et al. tested the effects of a transient NPA treatment on development of the gynoecia and expression from the DR5 reporter ${ }^{21}$. In general, treatment of the floral buds with NPA resulted in a spreading or delocalization of the DR5 signal. More defined patterns of expression seen in the wild type such as lateral foci and pre-vascular strand specific expression patterns were broadened into more diffuse patterns that encompassed a greater proportion of the developing primordium. The ectopic DR5 response was often quite pervasive in the valve tissues suggesting that NPA treatment increased the level of auxin signaling generally throughout the valve. These gene expression changes were observed between 7 and 24 hours after treatment and preceded morphological changes.

NPA treatment also resulted in alterations of patterning along the medio-lateral extent of the gynoecium ${ }^{21}$. After NPA treatment, expression from medial-domain expressed reporters (i.e. SHATTERPROOF2 [SHP2], KNOTTED-LIKE FROM ARABIDOPSIS THALIANA1/BREVIPEDICELLUS $[K N A T 1 / B P]$, and TAA1) was expanded into lateral positions. These experiments suggest that blocking of polar auxin transport results in a partial reassignment of lateral fates into medial fates or in an expansion of the extent of the medial domain at the expense of the lateral domain.

SHOOT MERISTEMLESS (STM), like KNAT1/BP, encodes a Class I KNOX transcription factor and is expressed early within the developing medial domain of the gynoecium as well as within the shoot apical meristem ${ }^{12}$. STM has a key function in the formation, organization and maintenance of meristematic potential in the shoot apical meristem ${ }^{12,34-36}$. STM maintains the pool of meristematic cells within the shoot apical meristem and more transiently at the center of the floral meristem, allowing carpel and placental development ${ }^{37}$. It would be interesting to look the expression pattern of STM in response to NPA treatment. Based on the observed expansion of the medial domain markers (i.e. SHP2, KNAT1/BP, TAA1) upon NPA treatment, one might expect an expansion of STM expression upon NPA treatment, however to our knowledge this has not yet been investigated. Additionally, the recent report of a role for STM and KNAT1/BP during cell expansion 
and differentiation of xylem in the cambium of Arabidopsis hypocotyls ${ }^{38}$ suggests that, in addition to their role in maintenance of meristematic potential in the medial domain, STM or KNAT1/BP might function in the later differentiation of medial domain structures or vasculature.

\section{PGP/ABCB-type auxin transporters are also important for proper auxin responses in the gynoecium}

In addition to the PIN family transporters, the ATP-binding cassette subfamily $B$ (ABCB)/MULTI-DRUG RESISTANT/ P-GLYCOPROTEIN (PGP) family proteins also function as auxin efflux transporters ${ }^{39,40}$. These transporters are typically localized in an apolar fashion and are thought to alter polar auxin flux by regulating the intracellular auxin concentration that is available for polar transport by PIN proteins ${ }^{41,42}$. PGP1 and PGP19 are expressed in the developing gynoecium and are differentially required in the medial and lateral domains. Larsson et al. reported that pgp1/pgp19 double mutants displayed a reduced ability to generate the lateral DR5 apical foci while the medial DR5 foci were largely unaffected in this double mutant ${ }^{21}$. These results suggest a role for PGP1 and PGP19 in auxin transport in lateral domains. Larsson et al. suggest that when PGP-dependent functions are blocked by NPA treatment or in the pgp1/19 double mutant, auxin becomes trapped in internal cell layers of the carpel and thus is not available for transport by PIN transporters in the epidermis. The broader expression domain of the PIN transporters in the medial domain (expression in epidermis as well as internal mesophyll layers) may in part explain why the medial domain is less sensitive to the application of NPA or the loss of PGP1 and PGP19 activity.

\section{Interactions between cytokinin and auxin during gynoecial patterning, medial domain} development and ovule initiation

\section{Auxin and cytokinin regulate gynoecial patterning}

The plant hormone cytokinin (see side bar) regulates the development of the shoot and root apical meristems ${ }^{43,44}$ and is required for proper development of key medial domain derived structures, including the ovules, as well as the valve margin (dehiscence zone) ${ }^{45}$. Reduced ovule formation is observed when cytokinin biosynthesis or perception is impaired ${ }^{46-51}$. Conversely, increasing cytokinin levels delay cell differentiation and enhance cell proliferation in the CMM-derived placental tissues and increase the number of ovules formed per gynoecium ${ }^{52,53}$. The exogenous application of the cytokinin benzylaminopurine (BAP) as well as the analysis of transgenic cytokinin overexpression lines suggest that cytokinin plays at least three roles during gynoecial development: 1) an early developmental role in stimulating cell proliferation in the medial domain 2) a later role in the development of the valve margin ${ }^{45}$, and a role in patterning along the apical-basal axis of the gynoecium $^{54}$.

Zuniga-Mayo et al. recently reported that the treatment of developing flowers with exogenous cytokinin, in addition to causing proliferation of medial domain structures, also alters apical-basal patterning within the gynoecium ${ }^{54}$. The observed apical-basal patterning defects were characterized by a reduction or loss of the valves and were similar to those caused by the blocking of auxin transport via NPA treatment. These results suggest interplay between auxin and cytokinin signaling pathways in the gynoecium. The similarity of the cytokinin and NPA treatment phenotypes suggests 
that cytokinin reduces polar auxin transport in the gynoecium. Furthermore, the enhanced sensitivity of auxin response factor19 (arf19) and arf7 mutant gynoecia to the application of BAP suggests that these two ARFS, in addition to $A R F 3 / E T T I N^{3,55}$, function in apical-basal patterning of the gynoecium ${ }^{54}$.

A large degree of cross-talk between the cytokinin and auxin signaling pathways has been shown to influence the development of the shoot and root apical meristem ${ }^{43,44}$. In peripheral portions of the SAM, auxin down regulates STM expression ${ }^{56,57}$ and reduces cytokinin biosynthesis ${ }^{58}$. Additionally auxin, acting through MP/ARF5, suppresses the expression of ARABIDOPSIS RESPONSE REGULATOR7 (ARR7) and $A R R 15$, two components of the cytokinin response pathway ${ }^{59}$. Given the meristematic nature of the gynoecial medial domain it seems likely that similar mechanisms of cross talk may shape medial domain development. Visualization of cytokinin and auxin responses in the gynoecium, using synthetic reporters (TCS-based and DR5-based, respectively), showed that auxin and cytokinin responses in the gynoecium tend to have complementary and mutually-exclusive expression patterns suggesting an antagonistic regulatory relationship between auxin and cytokinin ${ }^{15,45,60}$.

The NO TRANSMITTING TRACT (NTT) zinc finger-containing transcription factor previously identified as a regulator of transmitting tract development ${ }^{61}$ also plays a role in the development of the valve margin and the replum ${ }^{62,63}$. NTT activates the expression of KNAT/BP1 in the medial domain of the gynoecium, likely through the direct binding to the KNAT1/BP promoter sequences ${ }^{63}$. The KNAT1/BP and REPLUMLESS (RPL) transcriptional regulators form a protein complex that is important for replum development ${ }^{64}$. NTT physically interacts with itself as well as RPL, KNAT1/BP and STM and several other regulators of gynoecial development suggesting that it is a member of a multi component complex that regulates development within the medial domain ${ }^{63} . K N A T 1 / B P$ and STM stimulate cytokinin synthesis in the SAM via the transcriptional upregulation of AtIPT7 in the cytokinin biosynthesis pathway ${ }^{65,66}$. Thus the stimulation of $K N A T 1 / B P$ expression that is brought about by NTT action may support higher levels of cytokinin in the medial domain. This is consistent with the increase in the size of the replum that is observed upon exogenous cytokinin application as well as in response to NTT overexpression..

The splicing factor CLUMSY VEIN (CUV), the Arabidopsis ortholog of the eukaryotic DEAH-box RNAdependent ATPase Pre-mRNA-processing factor 16 (Prp16), affects the splicing and differential expression of key genes involved in auxin-mediated development ${ }^{67}$. CUV is required for efficient pre-mRNA splicing of several auxin biosynthesis genes including TAA1, TAR2 and several YUCCA family members. The levels of properly spliced transcripts of a number of $P I N$ genes, auxin receptor genes and auxin signaling genes were also reduced in cuv mutants. The expression and subcellular localization of the PIN1 protein was also altered in the cuv mutant roots. Consequently, cuv mutants exhibit a number of phenotypes that arise from altered auxin spatial distribution, as is corroborated by aberrant DR5-reporter expression. The cuv mutants exhibit embryonic defects, leaf vasculature defects, and ectopic vein formation in cotyledons, flowers and gynoecia. The apical-basal patterning of the gynoecium is also disrupted in cuv plants, with cuv mutants displaying shorter valves and longer gynophore and style domains.

\section{Auxin and cytokinin regulate CMM development and ovule initiation from the meristematic medial domain}


CUP-SHAPED COTYLEDON 1 (CUC1) and CUC2 encode a pair of paralogous NAC-domain containing transcription factors that are expressed within adaxial portions of the gynoecial medial domain ${ }^{68-71}$. In order to study the functions of CUC1 and CUC2 during the development of the meristematic medial domain, Kamiuchi et al. examined gynoecium development in cuc1 cuc2 double mutant plantlets that were regenerated from cuc1 cuc2 calli ${ }^{69}$. The gynoecial phenotypes (i.e. reduced and misplaced CMMs) indicate a redundant role for $C U C 1$ and $C U C 2$ in the initiation and placement of the CMM within the medial domain. STM expression was greatly reduced in the cuc1 cuc2 double mutant gynoecia, particularly in adaxial portions of the medial domain, indicating the CUC1 and CUC2 are required for the initiation of STM expression in the CMM. This is reminiscent of their role in the initiation of STM expression during the development of the embryonic shoot apical meristem ${ }^{71,72}$. In addition to its role in shoot apical meristem development (see above), STM plays a role in the maintenance of undifferentiated cells in the floral meristem ${ }^{34}$ as well as in the initiation of carpel development and in the formation or maintenance of the placental tissue of the medial domain ${ }^{37}$. Thus, much of the cuc1 cuc2 double mutant gynoecial phenotype may be due to the failure to activate STM in the developing CMM ${ }^{69}$. The expansion of FILAMENTOUS FLOWER (FIL) expression into portions of the medial domain in the cuc1 cuc2 double mutant suggests that CUC1 and CUC2 activities normally prevent valve differentiation in the medial domain, presumably through the activation of STM expression ${ }^{69}$.

Kamiuchi et al. also generated microRNA-resistant versions of CUC1 and CUC2 that were expressed at higher levels and in expanded domains within the gynoecium relative to the expression of the wild type genes. Plants expressing these microRNA-resistant CUC constructs displayed supernumerary $\mathrm{CMMs}$ in adaxial portions of the medial domain and generated filamentous structures from ectopic CMM-like structures in abaxial portions of the medial domain ${ }^{69}$. Correspondingly, STM expression is expanded. The formation of filamentous structures from abaxial replum is similar to, albeit less severe than, the phenotype of BAP-treated gynoecia ${ }^{45}$, again suggesting a role of cytokinin downstream of STM that is important for proliferation of cells of the $\mathrm{CMM}^{45,52}$.

In order to look at the function of CUC1, CUC2 and ANT during ovule initiation Galbiati et al. generated an RNAi construct to reduce the activity of CUC1 specifically in the developing ovules ${ }^{73}$. As cuc1 cuc2 double mutants don't form a shoot apical meristem, this CUC1_RNAi construct allowed the ovule specific reduction of CUC1 activity and thus enabled the analysis of cuc1 cUC2 double and cuc1 cuc2 ant triple mutant ovules. The analysis of the pPIN1:PIN1::GFP reporter in a cuc1_RNAicuc2 double mutant revealed that $C U C 1$ and $C U C 2$ are redundantly required for the expression and proper localization of PIN1 in the developing ovules. In wild type plants PIN1 is detected in epidermal cells and displays a polarized subcellular localization on the plasma membrane surface orientated toward the apex of the growing ovule primordium ${ }^{27}$. In the cuc1_RNAi cuc2 double mutants, PIN1 protein was detected weakly and throughout the ovule primordium and failed to efficiently localize to the plasma membrane in an polar manner, instead being detected in vacuoles and diffusely on plasma membranes in an apolar fashion ${ }^{73}$. Previous work had demonstrated that exogenous application of cytokinin could stimulate the expression of PIN1 ${ }^{74}$, and Galbiati et al. demonstrated that ovule loss and the reduction of PIN1 expression that was observed in the cuc1_RNAi cuc2 double mutant could be partially rescued by the exogenous application of cytokinin. Interestingly the loss of ovule primordia in the ant mutant was not rescued by the application of BAP suggesting that $A N T$ functions in a CUC1/CUC2-independent pathway. 
The expression of CUC1, CUC2 and ANT are stimulated by the MP/ARF5 auxin response factor through the direct interaction of MP/ARF5 with the cis-regulatory regions of these genes ${ }^{73,75}$. Galbiati et al. recently presented a model that proposes that auxin via the MP/ARF5 protein stimulates $A N T$ expression, and thus promotes cell proliferation in the placenta and ovules during early gynoecial development ${ }^{73}$ (Figure 3 ). In this model MP/ARF5 also directly stimulates the expression of $C U C 1$ and $C U C 2$ that redundantly regulate PIN1 expression through a non-cell autonomous action, allowing the formation of auxin maxima at the growing tip of the new ovule primordium. Cytokinin response, downstream of the CUC genes, is likely in part responsible for the CUC1/CUC2 promotion of PIN1 expression. At later stages of ovule development the auxin maxima at the apex of the developing ovule may repress $C U C$ gene expression, as has been demonstrated in leaves $^{76}$.

\section{Transition from floral meristem to gynoecial primordium}

\section{Auxin regulates the termination of the floral meristem and progression into the gynoecium}

The earliest steps in the specification of the medial and lateral gynoecial domains, and the degree to which the termination of the floral meristem and the formation of the gynoecium is mechanistically coordinated, remain unresolved. A recent paper by Liu et al. revealed a role for auxin and the auxin response factor ARF3 in floral meristem termination ${ }^{77}$. They show that ARF3 functions as a repressor of WUS transcription and this action is in part dependent on the transcription factor AGAMOUS (AG). Chromatin IP data indicate that ARF3 associates with the WUS cis-regulatory regions and this interaction is promoted by $A G$ function. These experiments also argued for a rather complex role for ARF3 in floral termination with ARF3 likely playing a direct role in WUS repression in the cells of the organizing center, while ARF3 may additionally function in a non-cell autonomous fashion outside the organizing center, exerting an indirect repression on WUS. The experiments of Liu et al. when taken together with those of Larsson et al., suggest that auxin plays a role in both the termination of the floral meristem ${ }^{77}$ as well as the early patterning of the medial and lateral domains of the gynoecium ${ }^{21}$ thus potentially linking these two processes mechanistically. However, the observation that NPA treatments have not been shown to regulate floral meristem determinacy is puzzling in this regard.

Another link between floral meristem termination and medial domain development is suggested by the work of Wynn et al. who recently demonstrated a role for the transcriptional regulator PERIANTHIA (PAN) in medial domain development and the subsequent formation of ovules ${ }^{78}$. PAN activates $A G$ at the transcriptional level in the center of the floral meristem and thus promotes the proper termination of the floral meristem ${ }^{79,80}$. AG functions as a repressor of WUS both directly and indirectly, as well as in concert with ARF3 as described above ${ }^{77,81-83}$. Wynn et al. demonstrate that in seu pan double mutants the floral meristem termination defects are enhanced and WUS expression is temporally extended ${ }^{78}$. Thus they propose that PAN and SEU act as activators of $A G$ in central portions of the flower. The enhanced indeterminacy in the pan seu double mutants is correlated with an enhanced loss of ovules suggesting a possible mechanistic link between these two developmental events. This apparent connection between floral meristem termination and ovule/medial domain formation was first noted by Zuniga-Mayo et al. in their study of jaiba crc double mutants ${ }^{84,85}$. JAIBA and $C R C$ are involved in the proliferation of the medial tissues and jaiba 
crc double mutants display both abnormal floral meristem determination phenotypes, as well as reduced formation of ovule primordia. A large number of other genes have been shown to function during floral meristem termination in Arabidopsis [see Ito and Bo (2015) for a recent review ${ }^{86}$ ] perhaps providing additional opportunities to explore the proposed mechanistic link between floral meristem termination and $\mathrm{CMM}$ /ovule formation.

\section{Conservation and divergence of gynoecial developmental mechanisms within eudicots}

\section{NGATHA (NGA) gene function is conserved in diverse eudicots indicating aspects of auxin regulation during gynoecial development are evolutionarily conserved}

The four Arabidopsis thaliana NGATHA (NGA) genes are a part of the RAV clade within the B3 family of transcription factors ${ }^{87,88}$. The Arabidopsis NGA genes act in a redundant manner to specify stigma and style development. The $n g a 1,2,3,4$ quadruple mutants (hereafter nga quad. mutants) display a severe loss of style and stigmatic tissue as well as apical splitting of gynoecia. The strong apical ring of DR5-based auxin response that is normally detected at the gynoecial apex, and that precedes the morphological development of the stigmatic and stylar tissues, is also not detected in the $n g a$ quad. mutants ${ }^{89}$. The comparison of transcriptomic profiles of gynoecia from wild type, $n g a$ quad. mutant and NGA3-overexpression lines has identified nearly 2,500 putative targets of NGA regulation within the gynoecium many of which function in auxin synthesis, transport or signaling ${ }^{89}$. The expression of the auxin biosynthesis genes YUCCA2, 4, 8, and TAA1 as well as AMIDASE1 (AMI1) are reduced or absent in the apical gynoecial tissues in $n g a 1,2,3,4$ quad. mutants ${ }^{88-90}$. Polar auxin transport may also be regulated by NGA genes through the repression of $P I D$ expression and the activation of the expression of WAG2 ${ }^{89}$.

Studies in the basal eudicot Eschscholzia californica and core eudicot Nicotiana benthamiana revealed that $N G A$ function is highly conserved across eudicots ${ }^{90}$. Using degenerate primers, one NGA gene was identified in E. californica (ECNGA) while BLAST searches of available draft genomic sequences identified two NGA genes in Nicotiana benthamiana, termed NtNGAa and NtNGAb. Expression patterns of ECNGA, NtNGAa and NtNGAb are similar in floral tissues in both species and resembles the spatial-temporal expression of AtNGA genes, including expression in placenta, ovules and apical portions of the gynoecium. Knockdown of NGA expression using viral induced gene silencing (VIGS) (see side bar) in E. californica and N. benthamiana produced reduction of style and stigmatic tissue and incomplete closure of the gynoecial tube. The similarity of these phenotypes with those observed in the $A$. thaliana nga quad. mutants ${ }^{87,88}$ indicates a conserved function for NGA genes across these eudicot species. This functional conservation also correlates with high level of putative structural and sequence similarity across NGA orthologs investigated ${ }^{90}$. BLAST searches identified a putative $N$. benthamiana YUCCA gene with high sequence similarity to $A$. thaliana YUC2 and YUC6 sequences. The expression of this putative N. benthamiana YUCCA gene was significantly reduced in styles and stigmas after VIGS-induced reduction of the expression of NtNGA. These data suggest that the regulatory relationship between NGA and YUC genes characterized in $A$. thaliana gynoecia may well be conserved in $N$. benthamiana. 
The miR156-SBP regulatory module may function differently during gynoecial development in Arabidopsis and tomato

In A. thaliana the microRNA156 (miR156) regulates expression of several members of the SQUAMOSA PROMOTER-BINDING PROTEIN-LIKE (SPL or SBP box) transcription factor family ${ }^{91}$. This $m i R 156-S B P$ regulatory module functions during gynoecial patterning and female fertility in Arabidopsis ${ }^{92}$. Overexpression of the miRNA156 in an $s p b 8$ mutant results in reduced ovule number, deformed septa and an absence of transmitting tract tissue, as well as a shortened style. These data indicate that the targets of miR156 act redundantly with $S P B 8$ (that is not targeted by miR156) to affect gynoecial development. These $s p b 8$; miR156 overexpression "double mutants" also displayed a hypersensitivity to NPA and a reduced expression of the YUCCA4::GUS reporter. In addition, SPB8 and targets of $m i R 156$ from the $S B P$ family were shown to interact genetically with ettin/arf3, spt and $c r c$, suggesting that the miR156-SBP regulatory module functions during gynoecial patterning by regulating auxin homeostasis.

Silva et al. (2014) recently demonstrated that the $m i R 156-S B P$ regulatory module also functions during gynoecial development in tomato ${ }^{93}$. However their results suggest that miR156-SBP module regulates tomato gynoecial development through pathways that differ somewhat from those in dry fruited species like Arabidopsis. In tomato the overexpression of AtmiR156 led to floral indeterminacy, the development of extra carpels, as well as to the development of fruits that contained ectopic meristematic structures. The AtmiR156 overexpression lines displayed an up-regulation of GOBLET (a NO APICAL MERISTEM/CUC-like gene) and TOMATO KNOTTED-LIKE2 (a class I KNOX gene) perhaps providing a mechanistic explanation for the presence of ectopic carpels and ectopic meristematic structures. Thus, although the miR156-SBP regulatory module appears to be important for gynoecial and fruit development in both tomato and Arabidopsis, the downstream targets of the module may be different in these two rather different fruit types. 
Auxin and auxin signaling

Auxin - A class of plant hormones originally defined by their ability to regulate growth via control of cell division and cell elongation. Recent reviews: ${ }^{18,94,95}$. Indole-3-acetic acid (IAA) is the most common plant auxin. The directional transport of auxins between the cells of developing organs can generate local auxin maxima or minima and thus support patterning events and patterns of organ growth. Two main types of auxin efflux transporters have been shown to participate in auxindependent patterning events: 1) PINFORMED (PIN) family members that are typically polarlylocalized within a given cell and support directionally-biased or orientated flows of auxin within the organ primordium ${ }^{96}$; and 2) $\mathrm{ABCB} / \mathrm{PGP}$ efflux transporters that are generally apolar localized within a cell, but may function in generating auxin patterns by regulating intracellular auxin concentration available to the PIN transporters ${ }^{41,42}$.

1-N-naphtylphthalamic acid (NPA) - A polar auxin transport inhibitor. NPA binds to ABCB/PGP transporters, but not to PIN transporters ${ }^{39-41}$. However NPA inhibits, either directly or indirectly, the ability of both $A B C B / P G P$ and PIN type reporters to transport auxin.

PINOID - a kinase that phosphorylates PIN family transporters and regulates their subcellular localization ${ }^{97,98}$

DR5 reporter- a synthetic auxin response reporter in which a known auxin responsive element is fused to a reporter gene to allow monitoring of auxin response in vivo ${ }^{99}$. Note that this is a reporter of the transcriptional response to auxin, not strictly a reporter of intracellular auxin levels.

TRYPTOPHAN AMINOTRANSFERASE OF ARABIDOPSIS1 (TAA1)/ TAA-RELATED 2 (TAR2) and YUCCAfamily genes - Genes that encode key enzymes in the auxin biosynthesis pathway ${ }^{100,101}$.

AMIDASE1 (AMI1) - Enzyme that converts indole-3-acetamide (IAM) to IAA in an alternative pathway to the TAA1/YUCCA route ${ }^{102}$

\section{Cytokinin synthesis and signaling}

Cytokinins: A class of adenine-derived plant hormones primarily associated with cell growth and differentiation during plant growth and development. Recent reviews: ${ }^{44,103-105}$. Cytokinin response and signaling involves a set of two-component histidine kinases. Cytokinins bind to membrane bound cytokinin receptors, ARABIDOPSIS HISTIDINE KINASES (AHKS), triggering a phosphor-relay ultimately causing the phosphorylation and activation of ARABIDOPSIS RESPONSE REGULATORS (ARRs). Phosphorylated type $\mathrm{B} A R R s$ activate transcription of cytokinin-responsive genes, including the type $\mathrm{A} A R R s$. The majority of type $\mathrm{A} A R R s$ act as inhibitors of cytokinin signaling. Cytokinin biosynthesis is catalyzed by enzymes encoded by members of the ATP/ADP ISOPENTENYLTRANSFERASE (IPT) gene family.

TCS (Two-Component-Output-Sensor) reporter: A synthetic cytokinin-response reporter that allows in vivo measurement of levels of cytokinin response in a given tissue or cell type. The reporter is 
driven by a promoter comprised of a concatenation of specific transcriptional elements that are responsive to cytokinin during immediate to early cytokinin response ${ }^{106}$.

Benzylaminopurine (BAP) - A synthetic cytokinin analogue. The exogenous application of BAP allows the determination of the effects of increased levels of cytokinin on development.

Viral induced gene silencing (VIGS) - using a plant viral vector to deliver an interfering RNA (RNAi) construct that can target a specific gene within the host plant and reduce the ability of a specific RNA transcript to make a functional product.

\section{Conclusion}

\section{The medial and lateral gynoecial domains develop via different mechanistic relationships}

One conclusion that is becoming increasingly clear is that the developmental programs within the medial domain and the lateral domains of the Arabidopsis gynoecium proceed by different trajectories and are likely under the control of different molecular mechanisms. Larsson et al. and Moubayidin and Ostergaard clearly demonstrate that the formation of the DR5 expression foci in the medial and lateral domains are mechanistically different ${ }^{21,22}$. Also the relationship between growth and auxin signaling appears substantially different in these two domains as well. Growth within the lateral domain appears to follow the existing paradigm for auxin flow and organ growth in lateral aerial organs: a reverse fountain flow pattern with an early apical maximum generates proximal to distal growth. What then is responsible for the growth of the medial domain if there are no early DR5 foci and vascular development is delayed in this domain? One possibility is that growth within the medial domain is coupled to lateral domain growth. Although some degree of coordination is perhaps likely, genetic evidence suggests that this is not absolute, as the growth of the medial and lateral domain can be genetically separated: tousled ettin (arf3) double mutants display a proliferation of medial tissues while lateral-derived valve tissues are greatly reduced ${ }^{107}$; and a somewhat complementary phenotype is observed in the leunig ant and seuss ant double mutants in which the valves form relatively normally in the lateral domains while the tissues from the medial domain are missing or are very reduced ${ }^{108,109}$.

\section{Relationship of auxin to medio/lateral, apical/basal and abaxial/adaxial patterning}

Another unanswered question relates to the relationship between auxin and cytokinin signaling, domain specific growth and the assignment of positional identities. Evidence from Larsson et al. suggests that early patterning events along the medio-lateral axis are regulated by auxin transport ${ }^{21}$. Early NPA treatment flattens the DR5 response foci and engenders an overall higher, but more diffuse, auxin response. This is correlated with the expansion of medial fates and a reduction in the extent of lateral fates. At least two possible mechanisms are consistent with this observation. It may be that the overall higher levels of auxin response favor the medial fates. Alternatively, medial fates are favored, not because auxin responses are higher across the primordium, but rather because the tight auxin response foci are not formed in the lateral domains when treated with NPA, and these tight foci are required for lateral domain outgrowth. In this second model, the growth of the medial domain would be favored as it is presumed not to require a well-canalized auxin flow to maintain growth. Larsson et al. also suggest that these early patterning defects might impact the subsequent 
elaboration of the apical-basal gynoecial structures. This is similar to previously proposed ideas that linked early abaxial-adaxial patterning or medio-lateral patterning events to the later elaboration of the apical-basal patterning of the gynoecium ${ }^{6,18,28}$. Hawkins and Liu (2014) recently proposed a model for auxin function during gynoecial development that invokes a role for auxin in patterning along the adaxial-abaxial extent of the early gynoecial primordium. They propose that the juxtaposition of adaxial and abaxial identities within the developing carpels is necessary for the upward growth of the valve domains ${ }^{28}$. This is based on similar models of growth of the leaf lamina 110 .

\section{Cross talk between cytokinin and auxin signaling pathways in the gynoecium}

In a manner similar to that observed in the shoot apical meristem, cytokinins appear to promote cell proliferation within and prevent the differentiation of the meristematic adaxial portions of the medial domain. This action of cytokinin contributes to the ability of the meristematic tissues to generate the medial domain-derived structures, particularly the ovules. Many observations suggest that there is significant crosstalk between the auxin and cytokinin signaling pathways during gynoecial apical/basal patterning, medial domain development and ovule initiation. The mechanisms of cross talk in the gynoecium may be similar to those observed in other structures, however a clear definition of the molecular mechanisms of auxin and cytokinin cross talk during gynoecial development awaits further investigations. Given the importance of the cytokininresponsive $A R R 5$ and $A R R 17$ regulators in mediating of auxin and cytokinin cross talk in the $\mathrm{SAM}^{59}$ it will be interesting to further explore the role of these ARR proteins in medial domain and gynoecial development.

\section{Acknowledgements}

We thank Emma Larsson and anonymous reviewers for helpful comments on the manuscript. Funding for this work came from NSF IOS grant\# 1355019 and NCARS grant \#NC02463 to RGF. We apologize to authors of related work that could not be cited here due to space limitations.

References

References:

1. Bowman JL, Baum SF, Eshed Y, Putterill J, Alvarez J. Molecular genetics of gynoecium development in Arabidopsis. Curr Top Dev Biol 1999, 45:155-205.

2. Hill JP, Lord EM. Floral Development in Arabidopsis-Thaliana - a Comparison of the WildType and the Homeotic Pistillata Mutant. Canadian Journal of Botany-Revue Canadienne De Botanique 1989, 67:2922-2936.

3. Sessions RA, Zambryski PC. Arabidopsis gynoecium structure in the wild and in ettin mutants. Development 1995, 121:1519-1532. 
4. Vaughn JG. The morphology and growth of the vegetative and reprodictive apices of Arabidopsis thaliana (L.) Heynh., Capsella bursa-pastoris (L.) Medic. and Anagallis arvensis (L.). J. Linn. Soc. Lond. Bot. 1955, 55:279-301.

5. Miksche JP, Brown JAM. Development of Vegetative and Floral Meristems of Arabidopsis Thaliana. American Journal of Botany 1965, 52:533-\&.

6. Sessions RA. Arabidopsis (Brassicaceae) flower development and gynoecium patterning in wild type and Ettin mutants. American Journal of Botany 1997, 84:1179-1191.

7. Dinneny JR, Weigel D, Yanofsky MF. A genetic framework for fruit patterning in Arabidopsis thaliana. Development 2005, 132:4687-4696.

8. Smyth DR, Bowman JL, Meyerowitz EM. Early flower development in Arabidopsis. Plant Cell 1990, 2:755-767.

9. Bowman JL, Smyth DR. CRABS CLAW, a gene that regulates carpel and nectary development in Arabidopsis, encodes a novel protein with zinc finger and helix-loop- helix domains. Development 1999, 126:2387-2396.

10. Chen Q, Atkinson A, Otsuga D, Christensen T, Reynolds L, Drews GN. The Arabidopsis FILAMENTOUS FLOWER gene is required for flower formation. Development 1999, 126:27152726.

11. Sawa S, Watanabe K, Goto K, Kanaya E, Morita EH, Okada K. FILAMENTOUS FLOWER, a meristem and organ identity gene of Arabidopsis, encodes a protein with a zinc finger and HMG-related domains. Genes Dev. 1999, 13:1079-1088.

12. Long JA, Moan El, Medford JI, Barton MK. A member of the KNOTTED class of homeodomain proteins encoded by the STM gene of Arabidopsis. Nature 1996, 379:66-69.

13. Savidge B, Rounsley SD, Yanofsky MF. Temporal relationship between the transcription of two Arabidopsis MADS box genes and the floral organ identity genes. Plant Cell 1995, 7:721733.

14. Cronquist A. The evolution and classification of flowering plants. 2nd ed. Bronx, N.Y., USA: New York Botanical Garden; 1988.

15. Ostergaard L. Don't 'leaf' now. The making of a fruit. Curr Opin Plant Biol 2009, 12:36-41.

16. Goethe JWv. Versuch die metamorphose der pflanzen zu erklären. Gotha,: C. W. Ettinger; 1790.

17. Taylor DW. Angiosperm Ovules and Carpels: Their Characters and Polarities, Distribution in Basal Clades, and Structural Evolution. Postilla 1991:1-40.

18. Larsson E, Franks RG, Sundberg E. Auxin and the Arabidopsis thaliana gynoecium. Journal of Experimental Botany 2013, 64:2619-2627.

19. Dresselhaus T, Schneitz K. The Role of Auxin for Reproductive Organ Patterning and Development. In: Zažímalová E, Petrášek J, Benková E, eds. Auxin and Its Role in Plant Development: Springer Vienna; 2014, 213-243.

20. Nemhauser JL, Feldman $\amalg$, Zambryski PC. Auxin and ETTIN in Arabidopsis gynoecium morphogenesis. Development 2000, 127:3877-3888.

21. Larsson E, Roberts CJ, Claes AR, Franks RG, Sundberg E. Polar Auxin Transport is Essential for Medial versus Lateral Tissue Specification and Vascular-mediated Valve Outgrowth in Arabidopsis Gynoecia. Plant Physiol 2014.

22. Moubayidin L, Ostergaard L. Dynamic Control of Auxin Distribution Imposes a Bilateral-toRadial Symmetry Switch during Gynoecium Development. Curr Biol 2014, 24:2743-2748.

23. Girin T, Paicu T, Stephenson P, Fuentes S, Korner E, O'Brien M, Sorefan K, Wood TA, Balanza $\mathrm{V}$, Ferrandiz $\mathrm{C}$, et al. INDEHISCENT and SPATULA interact to specify carpel and valve margin tissue and thus promote seed dispersal in Arabidopsis. Plant Cell 2011, 23:3641-3653.

24. Aloni $\mathrm{R}$, Aloni $\mathrm{E}$, Langhans $\mathrm{M}$, Ullrich $\mathrm{Cl}$. Role of auxin in regulating Arabidopsis flower development. Planta 2006, 223:315-328.

25. Okada K, Ueda J, Komaki MK, Bell CJ, Shimura Y. Requirement of the Auxin Polar Transport System in Early Stages of Arabidopsis Floral Bud Formation 
10.1105/tpc.3.7.677. Plant Cell 1991, 3:677-684.

26. Sorefan K, Girin T, Liljegren SJ, Ljung K, Robles P, Galvan-Ampudia CS, Offringa R, Friml J, Yanofsky MF, Ostergaard L. A regulated auxin minimum is required for seed dispersal in Arabidopsis. Nature 2009, 459:583-586.

27. Benkova E, Michniewicz M, Sauer M, Teichmann T, Seifertova D, Jurgens G, Friml J. Local, efflux-dependent auxin gradients as a common module for plant organ formation. Cell 2003, 115:591-602.

28. Hawkins C, Liu Z. A model for an early role of auxin in Arabidopsis gynoecium morphogenesis. Front Plant Sci 2014, 5:327.

29. Friml J, Yang X, Michniewicz M, Weijers D, Quint A, Tietz O, Benjamins R, Ouwerkerk PB, Ljung K, Sandberg G, et al. A PINOID-dependent binary switch in apical-basal PIN polar targeting directs auxin efflux. Science 2004, 306:862-865.

30. Christensen SK, Dagenais N, Chory J, Weigel D. Regulation of auxin response by the protein kinase PINOID. Cell 2000, 100:469-478.

31. Benjamins R, Quint A, Weijers D, Hooykaas P, Offringa R. The PINOID protein kinase regulates organ development in Arabidopsis by enhancing polar auxin transport. Development 2001, 128:4057-4067.

32. Huang F, Zago MK, Abas L, van Marion A, Galvan-Ampudia CS, Offringa R. Phosphorylation of conserved PIN motifs directs Arabidopsis PIN1 polarity and auxin transport. Plant Cell 2010, 22:1129-1142.

33. Furutani $M$, Nakano $\mathrm{Y}$, Tasaka M. MAB4-induced auxin sink generates local auxin gradients in Arabidopsis organ formation. Proc Natl Acad Sci U S A 2014, 111:1198-1203.

34. Endrizzi K, Moussian B, Haecker A, Levin JZ, Laux T. The SHOOT MERISTEMLESS gene is required for maintenance of undifferentiated cells in Arabidopsis shoot and floral meristems and acts at a different regulatory level than the meristem genes WUSCHEL and ZWILLE. Plant J 1996, 10:967-979.

35. Barton MK, Poethig RS. Formation of the Shoot Apical Meristem in Arabidopsis-Thaliana - an Analysis of Development in the Wild-Type and in the Shoot Meristemless Mutant. Development 1993, 119:823-831.

36. Clark SE, Jacobsen SE, Levin JZ, Meyerowitz EM. The CLAVATA and SHOOT MERISTEMLESS loci competitively regulate meristem activity in Arabidopsis. Development 1996, 122:15671575.

37. Scofield S, Dewitte W, Murray JA. The KNOX gene SHOOT MERISTEMLESS is required for the development of reproductive meristematic tissues in Arabidopsis. Plant J 2007, 50:767-781.

38. Liebsch D, Sunaryo W, Holmlund M, Norberg M, Zhang J, Hall HC, Helizon H, Jin X, Helariutta $\mathrm{Y}$, Nilsson $\mathrm{O}$, et al. Class I KNOX transcription factors promote differentiation of cambial derivatives into xylem fibers in the Arabidopsis hypocotyl. Development 2014, 141:43114319.

39. Murphy AS, Hoogner KR, Peer WA, Taiz L. Identification, purification, and molecular cloning of N-1-naphthylphthalmic acid-binding plasma membrane-associated aminopeptidases from Arabidopsis. Plant Physiol 2002, 128:935-950.

40. Noh B, Murphy AS, Spalding EP. Multidrug resistance-like genes of Arabidopsis required for auxin transport and auxin-mediated development. Plant Cell 2001, 13:2441-2454.

41. Mravec J, Kubes M, Bielach A, Gaykova V, Petrasek J, Skupa P, Chand S, Benkova E, Zazimalova E, Friml J. Interaction of PIN and PGP transport mechanisms in auxin distributiondependent development. Development 2008, 135:3345-3354.

42. Wang B, Bailly A, Zwiewka M, Henrichs S, Azzarello E, Mancuso S, Maeshima M, Friml J, Schulz A, Geisler M. Arabidopsis TWISTED DWARF1 functionally interacts with auxin exporter ABCB1 on the root plasma membrane. Plant Cell 2013, 25:202-214.

43. Su YH, Liu YB, Zhang XS. Auxin-cytokinin interaction regulates meristem development. Mol Plant 2011, 4:616-625. 
44. El-Showk S, Ruonala R, Helariutta Y. Crossing paths: cytokinin signalling and crosstalk. Development 2013, 140:1373-1383.

45. Marsch-Martinez N, Ramos-Cruz D, Irepan Reyes-Olalde J, Lozano-Sotomayor P, ZunigaMayo VM, de Folter S. The role of cytokinin during Arabidopsis gynoecia and fruit morphogenesis and patterning. Plant J 2012, 72:222-234.

46. Werner T, Hanus J, Holub J, Schmulling T, Van Onckelen H, Strnad M. New cytokinin metabolites in IPT transgenic Arabidopsis thaliana plants. Physiol Plant 2003, 118:127-137.

47. Hutchison CE, Li J, Argueso C, Gonzalez M, Lee E, Lewis MW, Maxwell BB, Perdue TD, Schaller $\mathrm{GE}$, Alonso JM, et al. The Arabidopsis histidine phosphotransfer proteins are redundant positive regulators of cytokinin signaling. Plant Cell 2006, 18:3073-3087.

48. Miyawaki K, Tarkowski P, Matsumoto-Kitano M, Kato T, Sato S, Tarkowska D, Tabata S, Sandberg G, Kakimoto T. Roles of Arabidopsis ATP/ADP isopentenyltransferases and tRNA isopentenyltransferases in cytokinin biosynthesis. Proc Natl Acad Sci U S A 2006, 103:1659816603.

49. Riefler M, Novak O, Strnad M, Schmulling T. Arabidopsis cytokinin receptor mutants reveal functions in shoot growth, leaf senescence, seed size, germination, root development, and cytokinin metabolism. Plant Cell 2006, 18:40-54.

50. Kinoshita-Tsujimura K, Kakimoto T. Cytokinin receptors in sporophytes are essential for male and female functions in Arabidopsis thaliana. Plant Signal Behav 2011, 6:66-71.

51. Higuchi M, Pischke MS, Mahonen AP, Miyawaki K, Hashimoto Y, Seki M, Kobayashi M, Shinozaki K, Kato T, Tabata S, et al. In planta functions of the Arabidopsis cytokinin receptor family. Proc Natl Acad Sci U S A 2004, 101:8821-8826.

52. Bartrina I, Otto E, Strnad M, Werner T, Schmulling T. Cytokinin regulates the activity of reproductive meristems, flower organ size, ovule formation, and thus seed yield in Arabidopsis thaliana. Plant Cell 2011, 23:69-80.

53. Ashikari M, Sakakibara H, Lin S, Yamamoto T, Takashi T, Nishimura A, Angeles ER, Qian Q, Kitano H, Matsuoka M. Cytokinin oxidase regulates rice grain production. Science 2005, 309:741-745.

54. Zuniga-Mayo VM, Reyes-Olalde JI, Marsch-Martinez N, de Folter S. Cytokinin treatments affect the apical-basal patterning of the Arabidopsis gynoecium and resemble the effects of polar auxin transport inhibition. Front Plant Sci 2014, 5:191.

55. Sessions A, Nemhauser JL, McColl A, Roe JL, Feldmann KA, Zambryski PC. ETTIN patterns the Arabidopsis floral meristem and reproductive organs. Development 1997, 124:4481-4491.

56. Furutani M, Vernoux T, Traas J, Kato T, Tasaka M, Aida M. PIN-FORMED1 and PINOID regulate boundary formation and cotyledon development in Arabidopsis embryogenesis. Development 2004, 131:5021-5030.

57. Heisler MG, Ohno C, Das P, Sieber P, Reddy GV, Long JA, Meyerowitz EM. Patterns of auxin transport and gene expression during primordium development revealed by live imaging of the Arabidopsis inflorescence meristem. Curr Biol 2005, 15:1899-1911.

58. Nordstrom A, Tarkowski P, Tarkowska D, Norbaek R, Astot C, Dolezal K, Sandberg G. Auxin regulation of cytokinin biosynthesis in Arabidopsis thaliana: a factor of potential importance for auxin-cytokinin-regulated development. Proc Natl Acad Sci U S A 2004, 101:8039-8044.

59. Zhao Z, Andersen SU, Ljung K, Dolezal K, Miotk A, Schultheiss SJ, Lohmann JU. Hormonal control of the shoot stem-cell niche. Nature 2010, 465:1089-1092.

60. Marsch-Martinez N, Reyes-Olalde JI, Ramos-Cruz D, Lozano-Sotomayor P, Zuniga-Mayo VM, de Folter S. Hormones talking: does hormonal cross-talk shape the Arabidopsis gynoecium? Plant Signal Behav 2012, 7:1698-1701.

61. Crawford BC, Ditta G, Yanofsky MF. The NTT gene is required for transmitting-tract development in carpels of Arabidopsis thaliana. Curr Biol 2007, 17:1101-1108.

62. Chung KS, Lee JH, Lee JS, Ahn JH. Fruit Indehiscence Caused by Enhanced Expression of NO TRANSMITTING TRACT in Arabidopsis thaliana. Molecules and Cells 2013, 35:519-525. 
63. Marsch-Martínez N, Zúñiga-Mayo VM, Herrera-Ubaldo H, Ouwerkerk PBF, Pablo-Villa J, Lozano-Sotomayor P, Greco R, Ballester P, Balanzá V, Kuijt SJH, et al. The NTT transcription factor promotes replum development in Arabidopsis fruits. The Plant Journal 2014, 80:69-

81.

64. Alonso-Cantabrana H, Ripoll JJ, Ochando I, Vera A, Ferrandiz C, Martinez-Laborda A. Common regulatory networks in leaf and fruit patterning revealed by mutations in the Arabidopsis ASYMMETRIC LEAVES1 gene. Development 2007, 134:2663-2671.

65. Yanai O, Shani E, Dolezal K, Tarkowski P, Sablowski R, Sandberg G, Samach A, Ori N. Arabidopsis KNOXI proteins activate cytokinin biosynthesis. Curr Biol 2005, 15:1566-1571.

66. Jasinski S, Piazza P, Craft J, Hay A, Woolley L, Rieu I, Phillips A, Hedden P, Tsiantis M. KNOX action in Arabidopsis is mediated by coordinate regulation of cytokinin and gibberellin activities. Curr Biol 2005, 15:1560-1565.

67. Tsugeki R, Tanaka-Sato N, Maruyama N, Terada S, Kojima M, Sakakibara H, Okada K. CLUMSY VEIN, the Arabidopsis DEAH-box Prp16 ortholog, is required for auxin-mediated development. The Plant Journal 2015, 81:183-197.

68. Ishida T, Aida M, Takada S, Tasaka M. Involvement of CUP-SHAPED COTYLEDON Genes in Gynoecium and Ovule Development in Arabidopsis thaliana. Plant and Cell Physiology 2000, 41:60-67.

69. Kamiuchi Y, Yamamoto K, Furutani M, Tasaka M, Aida M. The CUC1 and CUC2 genes promote carpel margin meristem formation during Arabidopsis gynoecium development. Front Plant Sci 2014, 5:165.

70. Aida M, Ishida T, Fukaki H, Fujisawa $H$, Tasaka M. Genes involved in organ separation in Arabidopsis: an analysis of the cup-shaped cotyledon mutant. Plant Cell 1997, 9:841-857.

71. Aida M, Ishida T, Tasaka M. Shoot apical meristem and cotyledon formation during Arabidopsis embryogenesis: interaction among the CUP-SHAPED COTYLEDON and SHOOT MERISTEMLESS genes. Development 1999, 126:1563-1570.

72. Hibara K, Takada S, Tasaka M. CUC1 gene activates the expression of SAM-related genes to induce adventitious shoot formation. Plant J 2003, 36:687-696.

73. Galbiati F, Sinha Roy D, Simonini S, Cucinotta M, Ceccato L, Cuesta C, Simaskova M, Benkova E, Kamiuchi Y, Aida M, et al. An integrative model of the control of ovule primordia formation. Plant Journal 2013, 76:446-455.

74. Bencivenga S, Simonini S, Benkova E, Colombo L. The transcription factors BEL1 and SPL are required for cytokinin and auxin signaling during ovule development in Arabidopsis. Plant Cell 2012, 24:2886-2897.

75. Yamaguchi N, Wu MF, Winter CM, Berns MC, Nole-Wilson S, Yamaguchi A, Coupland G, Krizek BA, Wagner D. A molecular framework for auxin-mediated initiation of flower primordia. Dev Cell 2013, 24:271-282.

76. Bilsborough GD, Runions A, Barkoulas M, Jenkins HW, Hasson A, Galinha C, Laufs P, Hay A, Prusinkiewicz $P$, Tsiantis $M$. Model for the regulation of Arabidopsis thaliana leaf margin development. Proc Natl Acad Sci U S A 2011, 108:3424-3429.

77. Liu X, Dinh TT, Li D, Shi B, Li Y, Cao X, Guo L, Pan Y, Jiao Y, Chen X. AUXIN RESPONSE FACTOR 3 integrates the functions of AGAMOUS and APETALA2 in floral meristem determinacy. The Plant Journal 2014:n/a-n/a.

78. Wynn AN, Seaman AA, Jones AL, Franks RG. Novel functional roles for PERIANTHIA and SEUSS during floral organ identity specification, floral meristem termination, and gynoecial development. Front Plant Sci 2014, 5:130.

79. Das P, Ito T, Wellmer F, Vernoux T, Dedieu A, Traas J, Meyerowitz EM. Floral stem cell termination involves the direct regulation of AGAMOUS by PERIANTHIA. Development 2009, 136:1605-1611. 
80. Maier AT, Stehling-Sun S, Wollmann H, Demar M, Hong RL, Haubeiss S, Weigel D, Lohmann JU. Dual roles of the bZIP transcription factor PERIANTHIA in the control of floral architecture and homeotic gene expression. Development 2009, 136:1613-1620.

81. Lenhard M, Bohnert A, Jurgens G, Laux T. Termination of stem cell maintenance in Arabidopsis floral meristems by interactions between WUSCHEL and AGAMOUS. Cell 2001, 105:805-814.

82. Sun $\mathrm{B}, \mathrm{Xu} \mathrm{Y}, \mathrm{Ng} \mathrm{KH}$, Ito $\mathrm{T}$. A timing mechanism for stem cell maintenance and differentiation in the Arabidopsis floral meristem. Genes Dev 2009, 23:1791-1804.

83. Liu X, Kim YJ, Muller R, Yumul RE, Liu C, Pan Y, Cao X, Goodrich J, Chen X. AGAMOUS terminates floral stem cell maintenance in Arabidopsis by directly repressing WUSCHEL through recruitment of Polycomb Group proteins. Plant Cell 2011, 23:3654-3670.

84. Zuniga-Mayo VM, Marsch-Martinez N, de Folter S. JAIBA, a class-II HD-ZIP transcription factor involved in the regulation of meristematic activity, and important for correct gynoecium and fruit development in Arabidopsis. Plant J 2012, 71:314-326.

85. Zuniga-Mayo VM, Marsch-Martinez N, de Folter S. The class II HD-ZIP JAIBA gene is involved in meristematic activity and important for gynoecium and fruit development in Arabidopsis. Plant Signal Behav 2012, 7:1501-1503.

86. Ito T, Bo S. Regulation of Floral Stem Cell Termination in Arabidopsis. Frontiers in Plant Science 2015, 6.

87. Alvarez JP, Goldshmidt A, Efroni I, Bowman JL, Eshed Y. The NGATHA distal organ development genes are essential for style specification in Arabidopsis. Plant Cell 2009, 21:1373-1393.

88. Trigueros M, Navarrete-Gomez M, Sato S, Christensen SK, Pelaz S, Weigel D, Yanofsky MF, Ferrandiz C. The NGATHA genes direct style development in the Arabidopsis gynoecium. Plant Cell 2009, 21:1394-1409.

89. Martinez-Fernandez I, Sanchis S, Marini N, Balanza V, Ballester P, Navarrete-Gomez M, Oliveira AC, Colombo L, Ferrandiz C. The effect of NGATHA altered activity on auxin signaling pathways within the Arabidopsis gynoecium. Front Plant Sci 2014, 5:210.

90. Fourquin C, Ferrándiz C. The essential role of NGATHA genes in style and stigma specification is widely conserved across eudicots. New Phytologist 2014, 202:1001-1013.

91. Schwab R, Palatnik JF, Riester M, Schommer C, Schmid M, Weigel D. Specific effects of microRNAs on the plant transcriptome. Dev Cell 2005, 8:517-527.

92. Xing S, Salinas M, Garcia-Molina A, Höhmann S, Berndtgen R, Huijser P. SPL8 and miR156targeted SPL genes redundantly regulate Arabidopsis gynoecium differential patterning. The Plant Journal 2013, 75:566-577.

93. Silva GFFe, Silva EM, da Silva Azevedo M, Guivin MAC, Ramiro DA, Figueiredo CR, Carrer H, Peres LEP, Nogueira FTS. microRNA156-targeted SPL/SBP box transcription factors regulate tomato ovary and fruit development. The Plant Journal 2014, 78:604-618.

94. Woodward AW, Bartel B. Auxin: regulation, action, and interaction. Ann Bot 2005, 95:707735.

95. Sauer M, Robert S, Kleine-Vehn J. Auxin: simply complicated. Journal of Experimental Botany 2013, 64:2565-2577.

96. Habets MEJ, Offringa R. PIN-driven polar auxin transport in plant developmental plasticity: a key target for environmental and endogenous signals. New Phytologist 2014, 203:362-377.

97. Bennett SRM, Alvarez J, Bossinger G, Smyth DR. Morphogenesis in Pinoid Mutants of Arabidopsis-Thaliana. Plant Journal 1995, 8:505-520.

98. Christensen SK, Dagenais N, Chory J, Weigel D. Regulation of Auxin Response by the Protein Kinase PINOID. Cell, 100:469-478.

99. Ulmasov T, Murfett J, Hagen G, Guilfoyle TJ. Aux/IAA proteins repress expression of reporter genes containing natural and highly active synthetic auxin response elements. The Plant Cell 1997, 9:1963-1971. 
100. Tao Y, Ferrer JL, Ljung K, Pojer F, Hong F, Long JA, Li L, Moreno JE, Bowman ME, Ivans L, et al. Rapid synthesis of auxin via a new tryptophan-dependent pathway is required for shade avoidance in plants. Cell 2008, 133:164-176.

101. Stepanova AN, Robertson-Hoyt J, Yun J, Benavente LM, Xie DY, Dolezal K, Schlereth A, Jurgens $\mathrm{G}$, Alonso JM. TAA1-mediated auxin biosynthesis is essential for hormone crosstalk and plant development. Cell 2008, 133:177-191.

102. Mano Y, Nemoto K, Suzuki M, Seki H, Fujii I, Muranaka T. The AMI1 gene family: indole-3acetamide hydrolase functions in auxin biosynthesis in plants. J Exp Bot 2010, 61:25-32.

103. Kieber JJ, Schaller GE. Cytokinins. The Arabidopsis Book / American Society of Plant Biologists 2014, 12:e0168.

104. Brenner WG, Ramireddy E, Heyl A, Schmülling T. Gene regulation by cytokinin. Frontiers in Plant Science 2012, 3.

105. Hwang I, Sheen J, Müller B. Cytokinin Signaling Networks. Annual Review of Plant Biology 2012, 63:353-380.

106. Müller B, Sheen J. Cytokinin and auxin interplay in root stem-cell specification during early embryogenesis. Nature 2008, 453:1094-1097.

107. Roe JL, Nemhauser JL, Zambryski PC. TOUSLED participates in apical tissue formation during gynoecium development in Arabidopsis. Plant Cell 1997, 9:335-353.

108. Liu Z, Franks RG, Klink VP. Regulation of gynoecium marginal tissue formation by LEUNIG and AINTEGUMENTA. Plant Cell 2000, 12:1879-1892.

109. Azhakanandam S, Nole-Wilson S, Bao F, Franks RG. SEUSS and AINTEGUMENTA mediate patterning and ovule initiation during gynoecium medial domain development. Plant Physiol 2008, 146:1165-1181.

110. Waites R, Hudson A. phantastica: a gene required for dorsoventrality of leaves in Antirrhinum majus. Development 1995, 121:2143-2154.

111. Wynn AN, Rueschhoff EE, Franks RG. Transcriptomic characterization of a synergistic genetic interaction during carpel margin meristem development in Arabidopsis thaliana. Plos One 2011, 6:e26231.

Figure captions

Figure 1. Structural components along the apical/basal and medial/lateral axes of the Arabidopsis gynoecium.

A) A scanning electron microscopic image of a mature Arabidopsis gynoecium. The stigma (stg), style (sty), carpel valve (cv), abaxial replum (abr), gynophore (gn), ovary (ovy) and valve margin/dehiscence zone $(\mathrm{dz})$ are indicated. $B$ and $C$ ) False-colored confocal gynoecial cross sections B) A stage 11 cross section. A plane of symmetry (indicated with a dashed line) divides the gynoecium into two component carpels. Ovules (ov)and septum (s) are indicated. C) A stage 8 cross section. Medial and lateral domains are indicated. The carpel margin meristem/medial ridge $(\mathrm{mr})$ is false colored pink. D) A scanning electron microscopic image of a developing gynoecium from a stage 7 flower. Dashed line indicates plane of symmetry that bisects the medial domain. E and F) Stage 7 floral cross sections from in situ hybridization experiments. E) CRC expression (brown product) is detected in the two lateral domains. F) STM expression is detected in the medial domain. Panels A, B and $C$ are adapted from Azhakanandam et al. ${ }^{109}$ with permission. Panel $D$ is adapted from Wynn et al. ${ }^{111}$ with permission. 
Figure 2. Diagrammatic representation of proposed patterns of auxin transport in the lateral and medial domains of a stage 7 gynoecium.

A) In the lateral domains auxin is transported predominantly via the PIN1 transporter and follows the "reverse fountain" model. Auxin flow in the abaxial and adaxial epidermal cell layers is toward the apex. Green circles indicate the lateral domain DR5 response foci. B) In the medial domain the flow of auxin in the abaxial epidermis is similarly toward the apex. However, in the adaxial epidermis and in subepidermal cells auxin transport is less polarized resulting in a less canalized (channelled) flow of auxin and in weaker and later-forming DR5 foci (smaller green dots). Note: the confocal longitudinal gynoecium images in A and B are for diagrammatic purposes and are both images of an oblique lateral plane section. $C$ and $D$ ) A diagram of a cross-sectional view of a stage 7 gynoecium. The dotted line in $A$ and $B$ indicates the plane of section for which auxin flows are represented in panels $A$ and $B$, respectively.

Figure 3-A model of ovule formation from the meristematic medial domain as proposed by Galbiati et al. ${ }^{73}$

See text for details. Figure 3 is reproduced from Galbiati et al. ${ }^{73}$ with permission.

\begin{tabular}{|l|l|}
\hline \multicolumn{1}{|c|}{ Subtopic } & \multicolumn{1}{c|}{ Article title } \\
\hline e.g., Fertilization to Gastrulation & e.g., Maternal mRNA breakdown \\
\hline & \\
\hline & \\
\hline
\end{tabular}



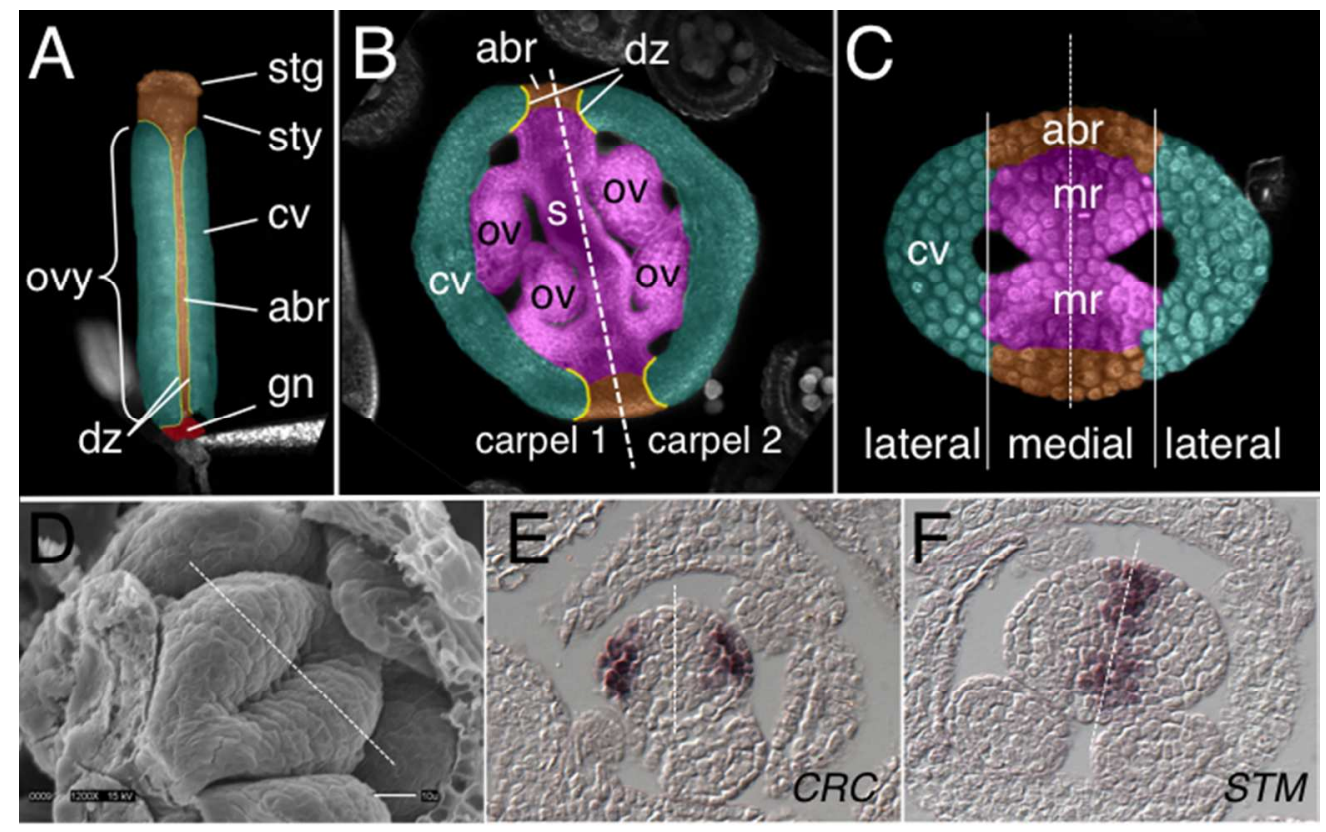

Figure 1. Structural components along the apical/basal and medial/lateral axes of the Arabidopsis gynoecium.

A) A scanning electron microscopic image of a mature Arabidopsis gynoecium. The stigma (stg), style (sty), carpel valve (cv), abaxial replum (abr), gynophore (gn), ovary (ovy) and valve margin/dehiscence zone (dz) are indicated. B and C) False-colored confocal gynoecial cross sections B) A stage 11 cross section. A plane of symmetry (indicated with a dashed line) divides the gynoecium into two component carpels. Ovules (ov)and septum (s) are indicated. C) A stage 8 cross section. Medial and lateral domains are indicated. The carpel margin meristem/medial ridge $(\mathrm{mr})$ is false colored pink. D) A scanning electron microscopic image of a developing gynoecium from a stage 7 flower. Dashed line indicates plane of symmetry that bisects the medial domain. E and F) Stage 7 floral cross sections from in situ hybridization experiments. E) CRC expression (brown product) is detected in the two lateral domains. F) STM expression is detected in the medial domain. Panels A, B and C are adapted from Azhakanandam et al. with permission. Panel D is adapted from Wynn et al. with permission. 

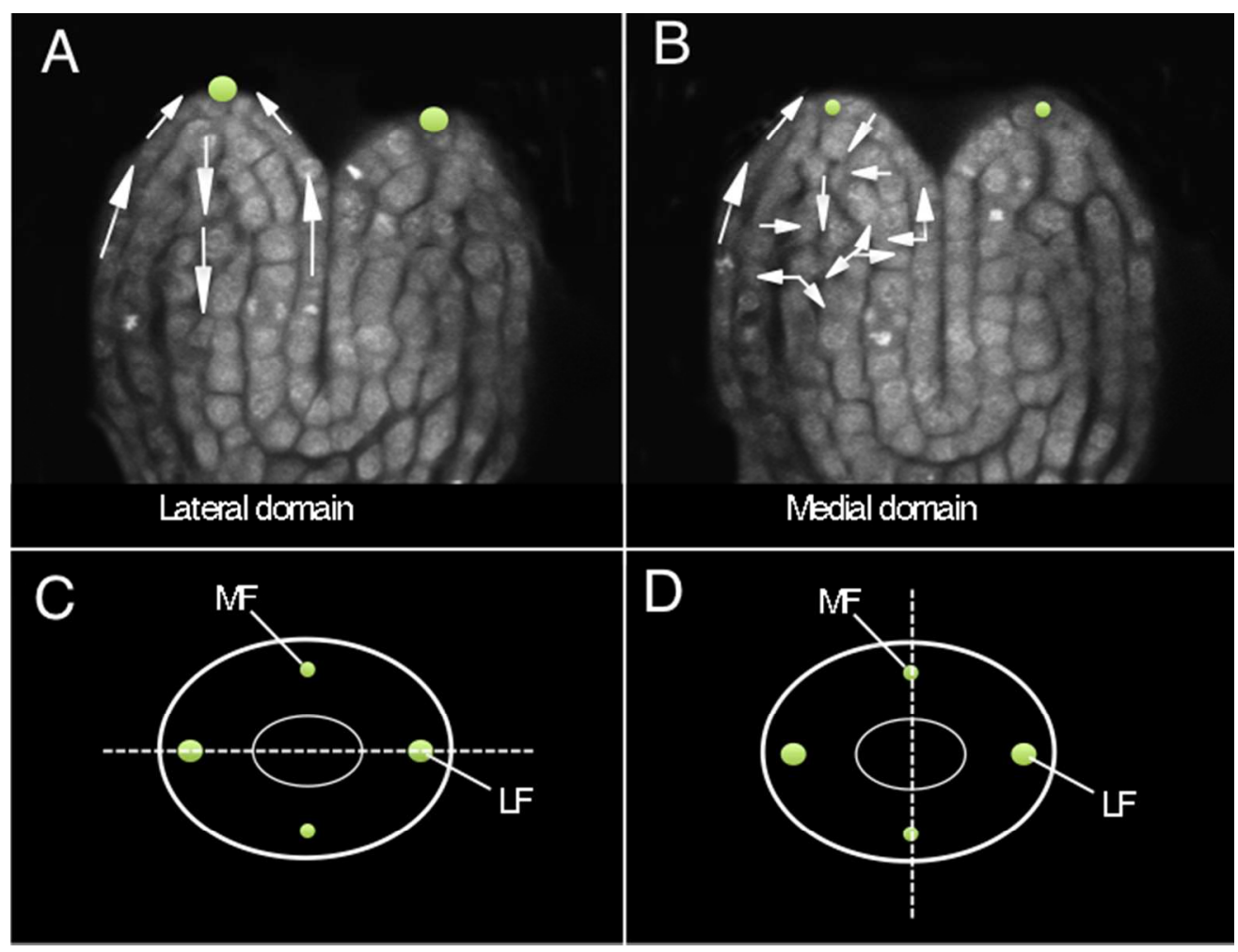

Figure 2. Diagrammatic representation of proposed patterns of auxin transport in the lateral and medial domains of a stage 7 gynoecium.

A) In the lateral domains auxin is transported predominantly via the PIN1 transporter and follows the "reverse fountain" model. Auxin flow in the abaxial and adaxial epidermal cell layers is toward the apex. Green circles indicate the lateral domain DR5 response foci. B) In the medial domain the flow of auxin in the abaxial epidermis is similarly toward the apex. However, in the adaxial epidermis and in subepidermal cells auxin transport is less polarized resulting in a less canalized (channelled) flow of auxin and in weaker and later-forming DR5 foci (smaller green dots). Note: the confocal longitudinal gynoecium images in A and B are for diagrammatic purposes and are both images of an oblique lateral plane section. $C$ and D) A diagram of a cross-sectional view of a stage 7 gynoecium. The dotted line in A and B indicates the plane of section for which auxin flows are represented in panels $A$ and $B$, respectively. $254 \times 193 \mathrm{~mm}(72 \times 72 \mathrm{DPI})$ 


\section{Figure 3 - A model of ovule formation from the meristematic medial domain as proposed by Galbiati et al.} See text for details. Figure 3 is reproduced from Galbiati et al. with permission.

$127 \times 84 \mathrm{~mm}(72 \times 72 \mathrm{DPI})$ 